\title{
ASSISTÊNCIA ESTUDANTIL E A EVASÃO ESCOLAR NO IFSP: ELEMENTOS PARA REFLEXÃO.
}

\author{
Michelli ApARECidA DAROS ${ }^{1}$ \\ ${ }^{1}$ Instituto Federal de Educação, Ciência e Tecnologia de São Paulo (IFSP) \\ $<$ michellidaros@gmail.com>
}

DOI: 10.21439/conexoes.v10i1.792

\begin{abstract}
Resumo. Este trabalho tem por objetivo apresentar os resultados encontrados na pesquisa de mestrado que teve por tema o estudo da evasão escolar e a atuação do Serviço Social no Instituto Federal de Educação, Ciência e Tecnologia de São Paulo (IFSP), realizada no período de 2008-2013. Nessa pesquisa, a partir de dados documentais e empíricos, foram identificados os motivos de evasão escolar de seis campi do IFSP. No presente artigo, apresentamos os motivos de evasão escolar, a interpretação sobre os dados encontrados e a análise das possibilidades de enfrentamento da evasão escolar pelas ações de Assistência Estudantil existentes no IFSP. No segundo momento, propomos alguns elementos para a reconfiguração das ações de Assistência Estudantil, a fim de construir a "Assistência Estudantil Ampliada".
\end{abstract}

Palavras-chaves: Educação Profissional e Tecnológica. Evasão Escolar. Assistência Estudantil.

\begin{abstract}
This study aims to put forward the results obtained on the master thesis about the school dropout and the Social Work's performance at the Instituto Federal de Educação, Ciência e Tecnologia de São Paulo (IFSP) carried out between 2008-2013. In this research, upon documentary evidence, the reasons for the school dropout of six campuses in the IFSP were identified. In this article, we present the reasons for school dropout, the interpretation of the collected data and the analysis of the possibilities of facing the school dropout by the existing Student Assistance actions in the IFSP. In a second phase, we propose some elements for the reconfiguration of the Student Assistance actions in order to build the "Extended Student Assistance".
\end{abstract}

Keywords: Professional and Technical Education. Student Dropout. Student Assistance.

\section{INTRODUÇÃO}

O presente trabalho tem por objetivo apresentar os resultados encontrados na dissertação de mestrado elaborada junto ao Programa de Estudos Pós-Graduados em Serviço Social da Pontifícia Universidade Católica de São Paulo, que teve como tema o estudo da evasão escolar e a atuação do Serviço Social no Instituto Federal de Educação, Ciência e Tecnologia de São Paulo (IFSP) no período de 2008-2013.

A pesquisa de mestrado supracitada teve por objetivo geral analisar as estratégias propostas e implantadas pelo Serviço Social no Programa de Assistência Estudantil do IFSP para a contenção da evasão escolar. Foram realizadas pesquisa bibliográfica, documental e empírica, em que seis assistentes sociais de diferentes campi foram entrevistadas. No decorrer desse trabalho, apresentamos fragmentos das entrevistas realizadas com assistentes sociais do IFSP. Com o objetivo de preservar a identidade das entrevistadas, nomes fictícios lhes foram atribuídos. A partir da pesquisa bibliográfica, foi possível a construção de um referencial teórico a respeito do Serviço Social crítico e da Educação na perspectiva histórico-crítica. A pesquisa documental possibilitou investigar os motivos da evasão escolar em seis campi do IFSP por meio de dados coletados pelas secretarias acadêmicas e questionários aplicados na saída do estudante da instituição.

No presente artigo, inicialmente, tratamos do atual contexto da Educação Profissional e Tecnológica, em que expomos leis e decretos que ampliaram o seu acesso à classe trabalhadora. No segundo momento, apresentamos os dados sobre a evasão no IFSP com o objetivo de interpretá-los e verificar os limites do enfrentamento da Assistência Estudantil aos motivos apresentados. Por último, elaboramos propostas para a reconfiguração das ações de Assistência Estudantil existentes. 


\section{TRABALHADORES E EDUCAÇÃO: A AM- PLIAÇÃO DO ACESSO À EDUÇAÇÃO PRO- FISSIONAL E TECNOLÓGICA}

No início do século XX, em 1909, é implantada a primeira experiência nacional institucionalizada de Educação Profissional, com a criação de dezenove Escolas de Aprendizes Artífices, pelo então presidente da república, Nilo Peçanha.

Ao longo do século XX, a Educação Profissional passa por modificações e aprimoramentos, sempre acompanhados pelas transformações econômicas do país e pela necessidade de preparo de mão-de-obra para o trabalho em fábricas, indústrias e comércio.

Na década de 1990, a Educação Profissional se torna Educação Profissional Tecnológica. São criados os CEFETs (Centros Federais de Educação, Ciência e Tecnologia), remetendo a importância do uso da tecnologia na formação de profissionais. Nesse momento, há uma ampliação do caráter pluralista dos cursos. Os CEFETs passam a ofertar cursos de educação de jovens e adultos, ensino médio integrado, ensino superior e pósgraduação.

Em 2008, são criados os Institutos Federais de Educação, Ciência e Tecnologia, os Institutos Federais (IFs). A criação e a expansão dos Institutos Federais, que ainda está em curso, tem por objetivo:

[...] promover a formação de profissionais qualificados, fomentando o desenvolvimento regional e estimulando a permanência de profissionais qualificados no interior do Brasil; potencializar a função social e o engajamento dos Institutos e Universidades como expressão das políticas do Governo Federal na superação da miséria e na redução das iniquidades sociais e territoriais (BRASIL, 2009).

Com a construção de novos Institutos Federais e ampliação da rede das unidades já existentes, a Educação Profissional e Tecnológica estabelece diálogos com as políticas sociais a fim de contribuir para o desenvolvimento socioeconômico.

A concepção de Educação Profissional e Tecnológica orienta os processos de formação com base nas premissas de integração e articulação entre ciência, tecnologia, cultura, conhecimentos específicos e do desenvolvimento da capacidade de investigação científica como dimensões essenciais à manutenção da autonomia e dos saberes necessários ao permanente exercício da laboralidade, que se traduzem nas ações de ensino, pesquisa e extensão. Por outro lado, tendo em vista que é essencial à Educação Profissional e Tecnológica contribuir para o progresso socioeconômico, as atuais políticas dialogam efetivamente com as políticas sociais e econômicas, dentre outras, em destaque para aquelas com enfoques locais e regionais (BRASIL 2010b p. 7).

Nos últimos anos, um conjunto de leis e iniciativas da rede federal de educação têm impactado na ampliação do acesso à educação à classe trabalhadora. O REUNI (Programa de Apoio aos Planos de Reestruturação e Expansão das Universidades Federais), criado em 2006, amplia o número de Universidades Federais e Institutos Federais no Brasil, gerando, consequentemente, mais matrículas na Educação Superior e na Educação Profissional e Tecnológica.

Cabe destacar também a redução e quase extinção de processos seletivos na forma de vestibulares e a substituição desses pelo Sistema de Seleção Unificada (SISU), criado em 2009, que é considerado um dos avanços frente à democratização do acesso à Educação Superior e à Educação Profissional e Tecnológica.

$\mathrm{O}$ acesso pelo SISU permite que estudantes de todo o país realizem a inscrição para ingressar em diversas Universidades e Institutos Federais sem a necessidade de comparecer à cidade da instituição de ensino para realizar uma prova teste. A nota do Exame Nacional do Ensino Médio (ENEM) é suficiente para classificar o estudante nas instituições e cursos selecionados. Essa nova forma de ingresso significa mais possibilidades de escolha aos estudantes e redução de custos em relação aos vestibulares, em que os candidatos realizam as provas na cidade sede da instituição.

Além do acesso pelo SISU-ENEM, em 2012, é publicada a Lei $n^{\circ} 12.711$, que dispõe sobre a reserva de vagas nas universidades e instituições de ensino técnico de nível médio. De acordo com a lei, cinquenta por cento das vagas são reservadas para estudantes que tenham cursado integralmente o ensino médio em instituições públicas. A partir da reserva de cinquenta por cento, vinte e cinco por cento são destinados aos estudantes cuja a renda per capita da família não ultrapasse um salário mínimo e meio. Outras porcentagens são reservadas a pretos, pardos e indígenas, conforme a região que a instituição de ensino se instala.

$\mathrm{Na}$ perspectiva de fortalecer as ações de acesso e permanência dos estudantes na conclusão de seus cursos, o Programa Nacional de Assistência Estudantil (PNAES) é criado, pelo Decreto $\mathrm{n}^{\mathrm{o}} 7.234 / 2010$. O programa tem por finalidade ampliar as condições de permanência dos jovens na educação pública federal e prevê o desenvolvimento de ações de Assistência Estudantil: moradia estudantil, alimentação, transporte, atenção à saúde, inclusão digital, cultura, esporte, creche, apoio didático-pedagógico e acesso, participação e aprendizagem de estudantes com deficiência, trans- 
tornos globais do desenvolvimento, altas habilidades e superdotação.

Por último, recordamos a importância do PRONATEC (Programa Nacional de Acesso ao Ensino Técnico e Emprego), criado pela Lei 12.513/2011, que tem por objetivo ampliar o acesso à Educação Profissional e Tecnológica, prioritariamente, aos estudantes da rede pública de ensino, aos estudantes da educação de jovens e adultos, trabalhadores e beneficiários dos programas de transferência de renda. Aos participantes do programa são ofertadas bolsas: a bolsa-formação estudante e a bolsa-formação trabalhador. A bolsa-formação estudante é voltada aos estudantes que realizam cursos técnicos, ou seja, de nível médio. A bolsa-formação trabalhador é destinada aos estudantes trabalhadores e aos beneficiários dos programas federais de transferência de renda que realizam cursos de formação inicial e continuada ou qualificação profissional.

A implantação de um conjunto de leis e programas que promovessem o acesso ao ensino superior e à Educação Profissional e Tecnológica, e também a permanência dos estudantes, como exemplo o PNAES, já citado anteriormente, têm tornado possível o ingresso da classe trabalhadora na Educação Profissional e Tecnológica.

\section{RECONHECENDO A EVASÃO ESCOLAR}

Apesar de todos os esforços governamentais, há um obstáculo na concretização da escolarização e profissionalização proposta pelos IFs: a evasão escolar. Verificase, ainda, um descompasso entre acesso e permanência - que se concretiza nos altos índices de evasão aferidos nos Institutos Federais de Educação, Ciência e Tecnologia pelo Tribunal de Contas da União (TCU, 2013). De acordo com o Acórdão no 506/2013 do TCU:

A evasão representa problema que alcança diferentes modalidades de ensino em maior ou menor medida. No Brasil, a educação profissional não foge a essa regra, sendo um importante vazamento que impede que boa parte dos alunos concluam seus respectivos cursos. [...] Quando se analisam as taxas de conclusão em nível nacional se situam em $46,8 \%$ para o médio integrado, $37,5 \%$ para o Proeja, 25,4\% para a Licenciatura, 27,5\% para o Bacharelado e $42,8 \%$ para os cursos de tecnólogo (TCU. 2013 p. 2)

A partir dos dados verificados pelo TCU, a conclusão dos cursos nas diversas modalidades ofertadas pelos Institutos Federais não chega a 50\% (cinquenta por cento), valor extremamente insuficiente às novas metas do Plano Nacional de Educação (PNE-2011-2020), em que é prevista a porcentagem de $90 \%$ para a taxa de conclusão dos cursos. Há um esvaziamento das salas de aula justamente no período de maior incremento ao acesso à Educação Profissional e Tecnológica.

"A evasão é um fenômeno social complexo, definido como a interrupção no ciclo de estudos"(BAGGI; LOPES, 2011, p. 356) Ao analisar os danos causados pela evasão, Silva Filho et al. (2007, p. 642):

[...] As perdas de estudantes que iniciam mas não terminam seus cursos são desperdícios sociais, acadêmicos e econômicos. No setor público, são recursos públicos investidos sem o devido retorno. No setor privado, é uma importante perda de receitas. Em ambos os casos, a evasão é uma fonte de ociosidade de professores, funcionários, equipamentos e espaço físico.

Os dados apontados por Silva Filho et al. (2007) são importantes; é preciso se atentar às questões dos recursos empenhados na educação no Brasil, mas, a questão qualitativa central é a de que a evasão escolar pode ser considerada uma potencial ameaça ao direito à educação. O enfrentamento da evasão escolar deve levar em conta aspectos da administração pública, mas, também o direito social à educação, presente na Constituição Federal de 1988.

A importância da compreensão do que é evasão não se dá apenas na definição do seu simples conceito, mas, no conjunto de reflexões sobre os motivos que a impulsionam, os danos causados à instituição e aos estudantes, bem como as estratégias para combatê-la. Afinal, a evasão não é apenas o não-cumprimento de metas educacionais e desperdícios de recursos, mas uma perda muito maior: a regressão da luta pela universalização da educação no Brasil.

\subsection{Os Motivos de Evasão no IFSP}

Com o objetivo de desvelar os motivos da evasão escolar no IFSP, foi realizada pesquisa documental que consistiu no levantamento de dados em secretarias acadêmicas e na identificação dos motivos de evasão escolar a partir de questionários respondidos por estudantes que não concluíram seus cursos, no período de 2008 a 2013. Como os levantamentos realizados pelos campi não foram executados de maneira sistemática e periódica, são apresentados os dados coletados pelos campi em diversos anos inseridos no período de 2008 a 2013. Os motivos de evasão, segundo os estudantes, são elencados por ordem de maior ocorrência na Tabela 1 .

Os diferentes motivos de evasão apresentados podem ser condensados em: trabalho, a não identificação com o curso escolhido e as dificuldades de aprendizado - que podem ser compreendidas no âmbito da defasa- 
ASSISTÊNCIA ESTUDANTIL E A EVASÃO ESCOLAR NO IFSP: ELEMENTOS PARA REFLEXÃO.

Tabela 1: Os motivos de Evasão no IFSP. Fonte: Autor

\begin{tabular}{|c|c|c|}
\hline Motivos & Metodologia & Campus \\
\hline $\begin{array}{c}\text { Horário de Trabalho; } \\
\text { dificuldades no aprendizado; } \\
\text { problemas familiares }\end{array}$ & $\begin{array}{l}\text { Questionário no momento de saída } \\
\text { do estudante (2013) }\end{array}$ & Araraquara \\
\hline $\begin{array}{l}\text { Problemas no trabalho; } \\
\text { sem identificação com o curso; } \\
\text { dificuldade no aprendizado }\end{array}$ & $\begin{array}{l}\text { Questionário no momento de saída } \\
\text { do estudante (2013) }\end{array}$ & Bragança Paulista \\
\hline $\begin{array}{l}\text { Fator externo ao ambiente escolar; } \\
\text { dificuldades na metodologia de ensino; } \\
\text { dificuldades na relação professor-aluno }\end{array}$ & $\begin{array}{l}\text { Questionário no momento } \\
\text { de saída doestudante. } \\
\text { Depoimento dos estudantes } \\
\text { evadidos (2011) }\end{array}$ & Itapetininga \\
\hline $\begin{array}{c}\text { Horário de trabalho incompatível; } \\
\text { passou no vestibular em outras instituições; } \\
\text { não se identificou com o curso }\end{array}$ & $\begin{array}{l}\text { Consulta aos dados } \\
\text { da secretaria (2012) }\end{array}$ & Hortolândia \\
\hline $\begin{array}{c}\text { Não conseguiu conciliar trabalho com o curso; } \\
\text { dificuldade em acompanhar o curso; } \\
\text { não se identificou com o curso }\end{array}$ & $\begin{array}{l}\text { Questionário no momento de saída } \\
\text { do estudante (2009) }\end{array}$ & São João da Boa Vista \\
\hline $\begin{array}{c}\text { Trabalho; } \\
\text { incompatibilidade com o curso; } \\
\text { mudança para outros cursos }\end{array}$ & $\begin{array}{l}\text { Questionário no momento de saída } \\
\text { do estudante (2013) }\end{array}$ & Sertãozinho \\
\hline
\end{tabular}

gem dos conteúdos escolares, das questões metodológicas e da relação professor-aluno.

Verifica-se que o principal motivo apontado pelos estudantes em todos os campi é o trabalho. Nesse artigo, nos inclinamos a compreender as questões que permeiam este motivo de evasão escolar. Faz-se necessária uma reflexão sobre o estudante do IFSP que também é trabalhador. Afinal, quem é o estudantetrabalhador?

[...] é o aluno trabalhador que quer mudar de vida, ter um estudo, ter essa possibilidade pra poder mudar mesmo a realidade dele, ele está apostando, está investindo. Para esse aluno, é muito sofrido e, geralmente, esse aluno que trabalha é do "chão de fábrica", ele é muitas vezes da zona rural, porque a gente tem essa realidade aqui. (Assistente Social Fátima)

Sobre a dificuldade de conciliação entre trabalho e estudo, é importante situar que o IFSP, que a priori, teria como público principal os trabalhadores, no momento em que estes se tornam trabalhadores que estudam, não tem apresentado condições que garantam sua permanência. A instituição, que tem por objetivo formar trabalhadores e capacitá-los, se torna esvaziada de trabalhadores-estudantes.

Vargas e Paula (2013), ao estudar as situações em que estudantes trabalham e estudam, verificam a existência do estudante-trabalhador e do trabalhadorestudante. No primeiro caso, quando o trabalho reali- zado é parcial e não ocupa todo o tempo livre do estudante, compreende-se que não há perda e incompletude das ações do trabalho e há a priorização dos estudos. Já no segundo caso, do trabalhador-estudante, os estudos são prejudicados, pois o trabalho integral é primordial na vida do aluno, fazendo com que o curso fique em plano secundário. É comum que o estudante escolha um curso compatível ao seu trabalho, sendo o curso, neste sentido, apenas um acessório do trabalho.

Aos estudantes que dependem do trabalho para manter suas condições mínimas materiais ou até as condições das pessoas que dependam do seu trabalho, é verificável a falta de tempo para os estudos e também, para a participação de atividades extracurriculares que as instituições propiciam. Ao mesmo tempo em que, sem o trabalho, não seria possível a estes alunos estudar. Eis a contradição: "Por vezes, o trabalho dificulta a escolarização, por vezes a ausência de trabalho impede a escolarização"(VARGAS; PAULA, 2013, p. 465).

Ao trazer dados sobre os estudantes da Educação Superior no Brasil, Vargas e Paula (2013) enfatizam que na faixa etária de 18 a 19 anos, $27 \%$ dos brasileiros podiam apenas estudar. Na faixa etária de 20 a 24 anos de idade, apenas $10,8 \%$ dos jovens brasileiros podiam estudar sem trabalhar (PNAD, 2006; IBGE, 2007 apud VARGAS; PAULA, 2013), ou seja, o universitário brasileiro, em geral, tem como característica principal o exercício do trabalho. Neste sentido: 
Parece razoável supor, e nossa experiência profissional confirma, que grande parte das dificuldades e mesmo do insucesso escolar de nossos alunos recaem sobre a dificuldade de conciliação entre trabalho e estudo. Desperdiçamos anualmente e cassamos todos os dias os sonhos de milhares de estudantes esgotados, frustrados e impotentes perante obrigações de trabalho e escolares inconciliáveis. Abandonados à própria sorte, o trabalhadorestudante e o estudante-trabalhador no Brasil se vêem hoje estimulados a ingressar na educação superior. A retórica legal e política supostamente amparam esse projeto, seja sob o signo da diminuição das desigualdades sociais, seja pelo da democratização da educação superior (VARGAS; PAULA 2013 p. 468)

Contudo, a Pesquisa Nacional de Amostra por Domicílio (PNAD) referente a 2012 (ANDRADE, 2013), mostra que a porcentagem de alunos na faixa etária de 18 a 24 anos que somente estudam aumentou para 14,5\%. Em relação ao ano de 2006, referenciado pelas autoras Vargas e Paula (2013), há o aumento da porcentagem de alunos que podem somente estudar. $\mathrm{Na}$ Figura 1, apresentamos informações sobre o PNAD referente a 2012.

\section{Atividade dos jovens de 15 a 29 anos}

\section{Em \%, por grupos de idade}

[1 Somente estuda - Trabalha e estuda $\quad$ Somente trabalha

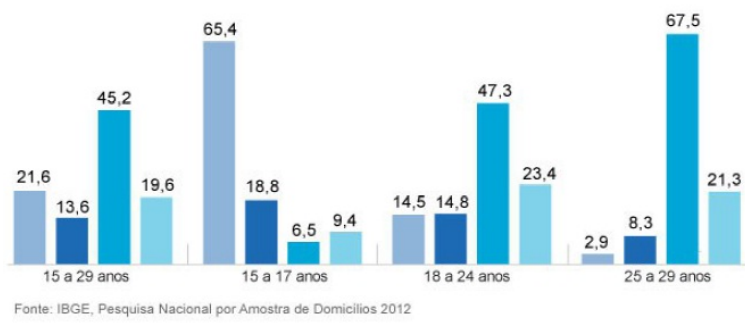

Figura 1: Atividades dos Jovens de 15 a 29 Anos (Em \%, Por Grupos de Idade). Fonte: Andrade 2013.

A partir de 2006, iniciadas as ações do REUNI e do PROUNI, há o aumento de vagas de matrículas nas Universidades Federais e a ampliação de bolsas de estudos integrais e parciais nas universidades privadas. Além disso, programas de assistência ao estudante e bolsas-permanência passam a integrar as ações com vistas à permanência dos estudantes nas Universidades/Institutos Federais e instituições privadas, respectivamente. Isto nos permite refletir a respeito do impacto destas ações no aumento de "jovens que apenas estudam"no ano de 2012, conforme o PNAD. Embora, não se possa afirmar que esta é uma das causas diretas para este aumento, não podemos, contudo, ignorar estas ações.

O estudante-trabalhador, principalmente aquele do período noturno, se encontra desprotegido das políticas públicas. De acordo com Vargas e Paula (2013), não há políticas educacionais com foco ao estudante trabalhador. No âmbito das leis do trabalho, o que se encontra na Consolidação das Leis do Trabalho (CLT) é apenas a possibilidade do estudante menor de 18 anos coincidir suas férias do trabalho com as férias escolares. Não há redução de horas para o trabalho, tampouco outras garantias. Esta situação compromete as possibilidades de estudos deste estudante que trabalha. Caso dependa do trabalho para se sustentar e para manter sua família, colocará sempre os estudos em segundo plano.

\subsection{A Assistência Estudantil no IFSP: Limites no Enfrentamento da Evasão Escolar}

Considerando que o trabalho é o principal motivo de evasão no IFSP, é necessário refletir a respeito dos enfrentamentos à evasão escolar. A redução da retenção e evasão escolar compõe o rol de objetivos do PNAES juntamente com a democratização das condições de permanência dos estudantes, a minimização dos efeitos das desigualdades sociais na permanência dos jovens na educação federal superior e a contribuição para a promoção da inclusão social pela educação. Todos os objetivos estão conectados e tem valor grandioso no que se propõe e tem a educação a sua via de realização. Porém, a não realização de um deles impede que todos os outros se realizem pela via da educação, falamos da evasão escolar - eis a importância de combatê-la.

As ações de Assistência Estudantil têm se constituído como principal enfrentamento da evasão escolar até então no IFSP. A respeito dos limites da Assistência Estudantil, uma das assistentes sociais entrevistadas afirma:

A Assistência Estudantil auxilia, mas ela não vai resolver todos os problemas. O pai de família, que é um trabalhador, que é quem garante a renda na casa, não vai sair do trabalho para ficar com uma bolsa ou auxílio, algo incerto. Ele precisa daquela garantia de renda do trabalho. Então, aí que eu fico pensando até que ponto que a Assistência Estudantil realmente garante a permanência desse aluno [...]. A questão passa por esse aluno que precisa sustentar a família e perpassa a incompatibilidade do horário de trabalho-estudo: a falta de tempo pra estudar. (Assistente Social Guiomar)

Atualmente, grande parte dos Institutos e Universidades Federais têm optado pela chamada "bolsificação da Assistência Estudantil", que nada mais é do que a 
transferência de renda realizada aos estudantes por intermédio dos auxílios alimentação, transporte, moradia, creche, dentre outros. Em grande parte dos Institutos Federais, não há restaurantes, moradias estudantis e outras estruturas para os estudantes. Apesar do Decreto $\mathrm{n}^{\mathrm{o}}$ 7.234, de 19 de julho de 2010, não definir metodologias para a execução das ações de Assistência Estudantil, observa-se a forte tendência para as ações de transferência de renda no âmbito da Assistência Estudantil, o que dá subsídios para que ela seja comparada à Política Nacional de Assistência Social. "A bolsificação da Assistência Estudantil é também consequência da tendência à assistencialização das políticas sociais, que no âmbito da educação superior, a assistência ao estudante é expressão máxima." ARCOVERDE; NASCIMENTO, 2012, p. 173).

O grande desafio é que com o caráter "bolsificador"das ações de Assistência Estudantil, as necessidades dos estudantes são atendidas de maneira focalizada e não, universalista. O caráter focalista visa o atendimento emergencial às necessidades dos estudantes, para que estes possam "manter-se"minimamente na cidade em que se situa a instituição de ensino. Além do mais, são selecionados os alunos com renda per capita baixa para receber as bolsas ou auxílios, o que evidencia o aspecto segmentário das ações.

De acordo com o Decreto n ${ }^{0} 7.234 / 2010$, são estabelecidas dez áreas de assistência ao estudante: moradia estudantil, alimentação, transporte, atenção à saúde, inclusão digital, cultura, esporte, creche, apoio pedagógico e acesso, participação e aprendizagem de estudantes com deficiência, transtornos globais do desenvolvimento, altas habilidades e superdotação. Devido ao orçamento insuficiente para atendimento de todos os estudantes inscritos no Programa de Assistência Estudantil, o IFSP tem cada vez mais limitado suas ações ao pagamento de auxílios alimentação, transporte e moradia. Com a "bolsificação", ações ligadas à cultura, apoio didático e acesso, participação e aprendizagem dos estudantes com deficiência, transtornos globais do desenvolvimento, altas habilidades e superdotação são, na maioria das vezes, inteiramente esquecidas e inexploradas pelos profissionais da Assistência Estudantil, seja porque não há equipe suficiente para o desenvolvimento das ações, seja porque não há planejamento estratégico que visualize a Assistência Estudantil para além da transferência de renda.

No IFSP, as áreas de Assistência Estudantil são compreendidas em duas modalidades de assistência. Na primeira modalidade, são compreendidas as ações para o enfrentamento da vulnerabilidade social, são elas: auxilio-alimentação, auxílio-creche, auxílio-material didáticopedagógico, auxílio-moradia, auxílio-saúde e auxílio-transporte. Esses auxílios são destinados, prioritariamente, aos estudantes em vulnerabilidade social, que apresentam renda per capita familiar até um salário mínimo e meio. As ações de cultura, esporte, inclusão digital, acesso e aprendizagem dos estudantes com deficiência, transtornos globais do desenvolvimento e superdotação correspondem à segunda modalidade, as ações universais, e são destinadas a todos os estudantes da instituição, independente de situação socioeconômica.

O desenvolvimento das ações elencadas acima se dá, invariavelmente, pelo pagamento de auxílios aos estudantes. Em 2013, no momento de realização dessa pesquisa, o IFSP contava com 26 campi. Na Figura 2 . é possível observar o número de campi que propiciam cada um dos auxílios financeiros do Programa de Assistência Estudantil (PAE) do IFSP.

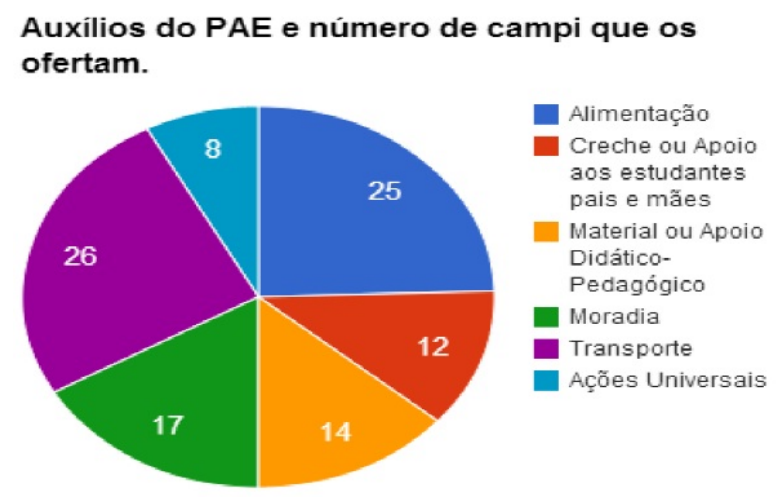

Figura 2: Auxílios Financeiros do Programa de Assistência Estudantil (PAE) IFSP 2013 Fonte: Autor (2014)

As ações de enfrentamento à vulnerabilidade social estão presentes em todos os campi, enquanto que as ações universais ainda não são realizadas pela maioria dos campi. Apenas oito campi conseguiram, no ano de 2013, propiciar ações de Assistência Estudantil na perspectiva universal, sem considerar o recorte de renda per capita dos estudantes. As principais ações universais realizadas em 2013 foram as visitas socioculturais (visitas a museus e exposições artísticas) e as ações de apoio à participação dos discentes em congressos e simpósios científicos.

Observa-se que o auxílio-transporte é ofertado por todos os campi e o auxílio-alimentação só não é ofertado por um campus, constituindo os dois auxílios juntos, os principais suportes do PNAES no IFSP. É importante ressaltar que, a somatória dos auxílios destinados a um estudante não ultrapassa o valor de um salário mí- 
nimo vigente.

O baixo valor dos auxílios estudantis pode estabelecer limites à permanência dos estudantes que trabalham, principal público evadido do IFSP, pois, muitas vezes, fica descartada a hipótese de abandonar o emprego para se dedicar aos estudos. A situação é acentuada quando os estudantes trabalhadores são os responsáveis não apenas pela manutenção de suas necessidades, mas pela manutenção de sua família. Além do mais, é importante ressaltar também que os auxílios financeiros são vulneráveis a dotações orçamentárias e procedimentos de fluxo de caixa do governo federal, não raramente, existem atrasos no recebimento dos auxílios pelos estudantes.

Ainda sobre o caráter "bolsificador"presente na Assistência Estudantil, Pereira (2012) afirma que as políticas sociais no Brasil, no atual contexto neoliberal, tendem a transferir recursos financeiros aos usuários ao invés de proporcionar estruturas adequadas para prestação dos serviços sociais. Nas palavras da autora, a monetarização da política social:

[...] não mais visa concretizar direitos sociais, mas fortalecer o mérito individual do pobre de conseguir, por meio do mercado, a satisfação de suas necessidades. As privilegiadas opções governamentais de repassar dinheiro aos pobres em lugar de garantir-lhes, como dever de cidadania, serviços sociais públicos, empregos e salários de qualidade, não são ingênuas e nem assistenciais. Tais opções apostam no poder mágico, fetichista, do dinheiro, que transforma os pobres em consumidores; e, no Brasil, também os transforma em uma significativa massa de pagadores de impostos, já que o sistema tributário brasileiro é altamente regressivo e grandemente incidente no consumo (PEREIRA 2012).

É verificável no contato com os profissionais e gestores do IFSP que os auxílios concedidos aos estudantes, muitas vezes, não condizem com os reais gastos para sua manutenção, principalmente nos municípios de médio e grande porte em que os custos de alimentação, transporte e moradia são elevados. Desta maneira, para complementar a renda, os estudantes se dedicam a trabalhos informais e precarizados, o que, de certa maneira, faz com que o tempo destinado aos estudos e à integração às atividades acadêmicas seja menor. Dificilmente, os estudantes que trabalham têm disponibilidade para participar de atividades de pesquisa e extensão, por exemplo.

Refletindo sobre os limites da Assistência Estudantil, a Assistente Social Lucy:

A Assistência Estudantil pra mim tem que ser uma coisa muito mais ampla do que ela é. Hoje a Assistência
Estudantil é um recurso financeiro e o que a gente espera dela é uma ação que seja de combate à vulnerabilidade. Então, quando você pensar na questão da vulnerabilidade, você não pode pensar só na questão financeira e não só no repasse de recursos, você tem que pensar numa questão ampla, de educação, de política de direito. (Assistente Social Lucy)

Atualmente, da maneira com que as ações vêm sendo conduzidas, a Assistência Estudantil tem se tornado um frágil mecanismo de defesa do direito à educação dos estudantes que trabalham. Para que mais estudantes e principalmente, os estudantes que trabalham, sejam atingidos pelas ações de Assistência Estudantil, faz-se necessário repensar as estratégias e a configuração da Assistência Estudantil como um todo.

\section{APONTAMENTOS PARA A CONSTRUÇÃO DA "ASSISTÊNCIA ESTUDANTIL AMPLI- ADA".}

Com base nas experiências do IFSP, ainda que não existam pesquisas aprofundadas sobre os impactos causados pela Assistência Estudantil, constata-se que ela tem oferecido apoio às necessidades apresentadas pelos estudantes, mas não tem, ainda, conquistado o seu objetivo de reduzir a evasão escolar.

Como já problematizado anteriormente, apenas o pagamento de auxílios financeiros que não ultrapassam o valor de um salário mínimo vigente, não têm impactado mudanças suficientes para que os estudantes pudessem priorizar os estudos. Referimo-nos, principalmente, aos estudantes trabalhadores.

Faz-se necessário situar a Assistência Estudantil como uma política educacional e universalista. Ampliar a atuação para além dos auxílios financeiros é um desafio eminente. O caráter universal da Assistência Estudantil possibilita que o atendimento aos estudantes seja ampliado, as ações não são traduzidas apenas em programas de bolsas e auxílios, mas em projetos ampliados de Assistência Estudantil, como a construção de moradias e restaurantes universitários, que possibilitam o atendimento de maior número de estudantes, e aumentam também, a responsabilidade e compromisso do governo federal com a permanência dos estudantes nas instituições de ensino e, consequentemente com a efetividade do direito à educação.

Assistência Estudantil, em sua razão de criação, tem por justificativa a defesa e a efetividade do direito à educação. Para Saviani (2013), o direito à educação é a condição, ainda que não suficiente, para o exercício de todos os direitos, sejam eles civis, políticos, sociais, econômicos ou de qualquer outra natureza. 
Para que o direito à educação seja assegurado como um facilitador do acesso e reivindicação por outros direitos, é necessário garantir aos estudantes muito mais do que o acesso e à permanência nas instituições de ensino. É preciso formar estudantes e trabalhadores críticos, ou seja, seres sociais ativos. E, é nessa perspectiva que acreditamos que a "Assistência Estudantil Ampliada"deve ser construída.

A "Assistência Estudantil Ampliada"é aquela que estreita laços com valores da democracia participativa e provê muito mais do que a permanência e conclusão dos estudantes em seus cursos, a "Assistência Estudantil Ampliada"se projeta como política de educação e, nela, a partir de práticas educativas, promove a formação de cidadãos críticos.

A seguir, elencamos alguns elementos para a construção e reconfiguração da Assistência Estudantil presente nos Institutos Federais. Acreditamos que os elementos apresentados não garantem o enfrentamento necessário ao trabalho, principal motivo de evasão do IFSP, sendo necessárias outras articulações externas para que as condições de permanência dos estudantes trabalhadores sejam ampliadas. Todavia, essas articulações apenas são possíveis no âmbito da "Assistência Estudantil Ampliada", a qual apresentamos alguns elementos para sua construção.

\subsection{A Implantação da Política Nacional de Assis- tência Estudantil}

Atualmente, na configuração de "programa", a Assistência Estudantil prevê dez áreas de atuação não sistematizadas pelos órgãos governamentais, cada instituição de ensino tem autonomia para realizá-las. Profissionais que trabalham com Assistência Estudantil têm empenhado esforços para que uma Política de Assistência Estudantil seja construída. A importância em consolidar uma política é que a política social amplia e direciona as ações de Assistência Estudantil, tencionando o direito ao acesso e permanência na educação.

As políticas sociais e a formação de padrões de proteção social são desdobramentos e até mesmo respostas e formas de enfrentamento - em geral setorializadas e fragmentadas - às expressões multifacetadas da questão social no capitalismo, cujo fundamento se encontra nas relações de exploração do capital sobre o trabalho.(NETTO apud BEHRING; BOSCHETTI, 2007, p. 51).

O estudo e análise das políticas sociais devem levar em conta a sua múltipla causalidade, as conexões internas, as relações entre suas diversas manifestações e dimensões (BEHRING; BOSCHETTI, 2007, p. 43). A política social tem dimensões históricas, econômicas, políticas e culturais - estas não se isolam ou se complementam, mas se entrelaçam.

A construção da Política Nacional de Assistência Estudantil deve considerar o atual contexto da reforma educacional no país - a emergência da classe trabalhadora no acesso aos cursos superiores e técnicos; a perspectiva neoliberal que dita os rumos da educação superior no país, as necessidades dos estudantes - a sua origem sociocultural, sua configuração socioeconômica e o momento histórico que propicia a intencionalidade da democratização do ensino superior e da Educação Profissional e Tecnológica. Além do mais, o debate sobre a abrangência do público da Assistência Estudantil se faz necessário nesse momento. É possível que a Assistência Estudantil seja ampliada aos estudantes do ensino médio, fundamental e infantil?

$\mathrm{Na}$ medida em que a Assistência Estudantil deixa de ser um programa para se tornar uma política, se amplia o comprometimento dos entes governamentais com o financiamento de ações e programas. Consequentemente, se amplia o leque de participação da população, principalmente, de estudantes nas decisões sobre as ações de Assistência Estudantil. Conselhos e conferências podem ser realizados com o objetivo de efetivar o controle social.

Atualmente, no âmbito nacional dos Institutos $\mathrm{Fe}$ derais não há fórum, câmara, comissão ou comitê institucionalizado que planeje, discuta e estude os impactos dos programas de Assistência Estudantil. As decisões orçamentárias são realizadas pelo Conselho Nacional das Instituições da Rede Federal de Educação Profissional, Científica e Tecnológica (CONIF) e não envolvem número expressivo de profissionais representantes da Assistência Estudantil, pois, muitas vezes, a Assistência Estudantil não está inserida em diretoria ou pró-reitoria específica nos Institutos Federais, ficando imersa às ações das Pró-Reitorias de Ensino ou Extensão.

A Assistência Estudantil das Universidades Federais se organiza de maneira diferente; os profissionais de Assistência Estudantil compõem grupos de trabalho regionais e nacionais no Fórum Nacional de PróReitores de Assuntos Comunitários e Estudantis (FONAPRACE). São vários os grupos, como exemplo, grupo de trabalho da moradia estudantil, alimentação, saúde do estudante, todos referenciados nas áreas de atuação do PNAES.Atuante há mais de 25 anos, o FONAPRACE tem desempenhado papel fundamental nas reivindicações para ampliação dos recursos de Assistência Estudantil, ao mesmo tempo em que tem elaborado estudos sobre o perfil socioeconômico dos estudantes do ensino superior público federal. 
Com a criação da Política de Assistência Estudantil, as ações e recursos já existentes são ampliados, além do fortalecimento da participação da população nas decisões sobre a política e também o compromisso da defesa do direito à educação.

\subsection{A Construção e Aprimoramento de Infraestru- tura nos Campi}

Embora restaurantes e moradias estudantis sejam comuns às Universidades Federais, essas estruturas ainda são novidades para os Institutos Federais. Alguns deles, com o aproveitamento de estruturas anteriores das Escolas Agrotécnicas Federais, como exemplo o Instituto Federal de Educação, Ciência e Tecnologia de Goiás, conseguem fornecer alimentos aos seus estudantes.

Aos campi dos IFs recém-criados, são encontrados refeitórios, muitas vezes, com capacidade bem menor de acomodação do que deveriam ter. Nas instituições onde não há restaurantes para estudantes, a alimentação é ofertada em forma de bolsa/auxílio financeiro, que por um lado, amplia as opções de alimentação dos estudantes, mas, devido ao baixo valor pago, quase sempre resulta em alimentação não-balanceada. Outra questão à alimentação paga por meio de bolsas e auxílios é a de que ela se restringe aos estudantes selecionados pelos programas de Assistência Estudantil.

Embora não exista legislação específica que garanta a alimentação escolar no ensino superior, ela é garantida aos cursos de nível médio, inclusive à educação de jovens e adultos pelo Programa Nacional de Alimentação Escolar (PNAE), atualizado pela Lei 11.947/2009. Muitos Institutos Federais têm faltado com o dever de fornecer alimentos aos estudantes de nível médio e educação de jovens e adultos.

É necessário um plano de construção e ampliação de restaurantes universitários para que a alimentação seja ofertada de maneira universal, não apenas aos estudantes selecionados pela Assistência Estudantil, mas a todos os estudantes e servidores da instituição. Além da alimentação estudantil, outra área do PNAES necessita de infraestrutura para realmente atender às necessidades dos estudantes: a moradia estudantil.

Assim como os restaurantes universitários, as moradias estudantis já existem nas Universidades Federais, contudo, há várias reivindicações estudantis para a ampliação da estrutura das moradias, a fim de atender mais estudantes universitários. Segundo Silveira (2012), as primeiras experiências de casas de estudantes no Brasil foram a construção da Casa do Estudante em Paris em 1928 para estudantes brasileiros que lá foram estudar e a construção da Casa do Estudante no Rio de Janeiro em 1930
Poucos são os Institutos Federais que possuem a infraestrutura para a moradia estudantil. Em caso semelhante aos restaurantes, as estruturas das antigas escolas agrotécnicas também foram aproveitadas.

As moradias estudantis têm papel decisivo na permanência e conclusão dos cursos pelos estudantes, principalmente, em grandes cidades onde a especulação imobiliária faz com que os aluguéis se tornem exorbitantes próximos às instituições de ensino. Ainda na perspectiva de "bolsificação", nota-se, muitas vezes, a insuficiência do valor recebido pelo estudante para custear a sua moradia.

Além das questões relacionadas à permanência dos estudantes, a moradia estudantil contribui para a convivência comunitária estudantil. Em muitas "casas dos estudantes"são realizadas experiências de autogestão em que os próprios estudantes elegem as regras de funcionamento das casas.

\subsection{Composição das Equipes Básicas de Assistên- cia Estudanti}

Inicialmente, é preciso demarcar a equipe básica dos programas de Assistência Estudantil. Atualmente, verifica-se, em grande parte dos Institutos Federais a concentração das atividades de Assistência Estudantil no grupo de assistentes sociais da instituição, sem a pré-definição de uma equipe básica. Nas universidades, com a chegada de recursos do PNAES e com a "bolsificação"das ações, houve, em alguns casos, o desmonte das equipes existentes; psicólogos e pedagogos deixaram a Assistência Estudantil para atuar em outros setores das instituições. No momento, não há legislação em âmbito nacional que referencie a equipe básica de Assistência Estudantil.

No IFSP, está em curso um projeto de implantação do Serviço Sociopedagógico. Cada campus terá uma equipe composta por assistentes sociais, pedagogos, psicólogos e técnicos em assuntos educacionais (TAEs). A equipe será responsável pelo acompanhamento do processo de ensino-aprendizagem de estudantes de todas as modalidades de ensino, pelas questões referentes à Assistência Estudantil e pelas ações inclusivas da instituição.

Apesar das várias áreas do PNAES exigirem conhecimentos de diversas áreas para serem desenvolvidas, a tendência "bolsificadora"das ações têm reduzido o caráter multidisciplinar da Assistência Estudantil no IFSP. A configuração de todas as áreas da Assistência Estudantil em repasse financeiro tem esvaziado os múltiplos saberes profissionais existentes na instituição, ficando a execução das ações de Assistência Estudantil sob a responsabilidade de assistentes sociais, profissionais com- 
petentes a realizar a análise socioeconômica para a seleção dos estudantes que receberão os auxílios. É importante ressaltar que a "bolsificação"das ações de Assistência Estudantil, da mesma maneira com que esgota as possibilidades de trabalhos multiprofissionais, também empobrece o leque de ações dos assistentes sociais.

A Assistência Estudantil modelada exclusivamente por auxílios e bolsas traz à tona outra questão: a de que ela é também uma política voltada exclusivamente aos que necessitam dos auxílios. O decreto $\mathrm{n}^{\mathrm{0}} 7.234 / 2010$, em seu Art. $5^{\circ}$ clarifica que o PNAES deve atender prioritariamente estudantes oriundos da rede pública de educação básica ou com renda familiar per capita de até um salário mínimo e meio. Portanto, a Assistência Estudantil não deve se desenvolver como uma política prioritária e não exclusiva a determinado público.

O trabalho multiprofissional na Assistência Estudantil permite que o atendimento integral aos estudantes seja realizado. $\mathrm{O}$ atendimento e acompanhamento dos estudantes, independente da concessão de bolsas e auxílios, sobretudo com o objetivo de formar integralmente os estudantes para a vida social crítica, contribui para a formação de estudantes socialmente ativos, assim como colabora com a construção da identidade da Assistência Estudantil como uma política educacional de caráter universal, a política de Assistência Estudantil para todos e não para um grupo selecionado como "vulnerável".

Além de profissionais já conhecidos da equipe de Assistência Estudantil, como assistentes sociais, pedagogos, psicólogos e nutricionistas, é importante mencionar que professores, embora na maioria das vezes, não componham as equipes, têm papel fundamental para o desenvolvimento das ações. O professor é uma espécie de ponte entre os estudantes em sala de aula e a equipe multiprofissional. O professor não apenas pode se tornar um parceiro da equipe multiprofissional, podendo prestar orientações importantes à equipe como, também, pode ser orientado pelos profissionais da Assistência Estudantil em determinadas situações

É necessária a sistematização da prática profissional das profissões inseridas na Assistência Estudantil. A divulgação de estudos acadêmicos e relatos de experiência podem auxiliar nesse momento de construção das equipes e reivindicação por maior número de profissionais para a área.

\subsection{Articulação das Ações de Assistência Estu- dantil com Bolsas e Estágios}

É comum a existência de outras bolsas, como bolsa pesquisa e extensão, nas Universidades e Institutos Federais. Os critérios para concessão dessas bolsas, geral- mente, não são socioeconômicos e estão correlacionados ao mérito acadêmico. No momento em que os auxílios prestados pela Assistência Estudantil se tornam insuficientes para a permanência dos estudantes, é importante o incentivo da participação desses estudantes em outros programas de bolsas. Nessa situação, além de contribuir para a permanência e manutenção dos estudantes, o desenvolvimento acadêmico e a promoção do pertencimento do estudante na instituição também são fortalecidos. A possibilidade de aliar o estágio remunerado com os auxílios da Assistência Estudantil também fortalece o desenvolvimento acadêmico e profissional.

A conciliação entre auxílios da Assistência Estudantil com bolsas e estágios remunerados permite, em certa medida, evitar o trabalho precarizado de estudantes que não conseguiriam dar seguimento aos estudos apenas com os auxílios da Assistência Estudantil. Essa conciliação pode ser uma estratégia para evitar a evasão dos estudantes que trabalham, principal público evadido do IFSP, como já exposto.

\subsection{Ações de Divulgação Para Além da Instituição de Ensino}

Em alguns Institutos e Universidades Federais, a divulgação sobre ações de Assistência Estudantil à comunidade externa já ocorre, cabe aqui ressaltar a sua importância. Visitas às escolas de nível médio ou fundamental para divulgar as ações de Assistência Estudantil, assim como informações no endereço eletrônico da instituição contribuem para disseminar as possibilidades de apoio à permanência que as instituições ofertam, e por fim, promover o acesso aos cursos ofertados.

\subsection{Articulações com o Movimento Estudantil}

É importante que os setores responsáveis pela Assistência Estudantil estejam articulados com as representações estudantis. Juntos, eles podem propor ações culturais, de prevenção às drogas e promoção da saúde, como exemplo. Grêmios e diretórios acadêmicos são organizações próximas dos estudantes em geral e, é possível que a comunicação com os estudantes seja facilitada. Estas organizações também podem contribuir criticamente com propostas de melhoria dos atendimentos e infraestrutura nas instituições de ensino, além de propor novas práticas à instituição. É preciso estar atento às reivindicações e necessidades estudantis e a articulação com o movimento estudantil pode auxiliar nestas questões. 
ASSISTÊNCIA ESTUDANTIL E A EVASÃO ESCOLAR NO IFSP: ELEMENTOS PARA REFLEXÃO.

\subsection{Criação de Observatórios de Assistência Estu- dantil}

É preciso acompanhar e estudar os impactos das ações de Assistência Estudantil em âmbito nacional. A criação de grupos de estudos com o intuito de observar o perfil socioeconômico dos estudantes ingressantes nos IFs, o perfil do público atendido pelos programas e o alcance dos objetivos da Assistência Estudantil a curto, médio e longo prazo são trabalhos a serem sistematizados em um ou mais observatórios, ou seja, grupos de estudos e coleta de dados sobre as ações de Assistência Estudantil. Os Observatórios de Assistência Estudantil podem ser compostos por profissionais da Assistência Estudantil, estudantes e docentes.

\section{CONCLUSÃO}

Por fim, compreendemos que o ingresso dos trabalhadores na Educação Profissional e Tecnológica é uma conquista que pode permitir que outros acessos sejam ampliados a este público. Embora apresentemos os limites atuais da Assistência Estudantil no IFSP, principalmente, em relação ao suporte aos estudantes que trabalham, e os desafios do PNAES em âmbito nacional como exemplos: a necessidade de formação de equipes básicas, a importância da criação de alternativas à "bolsificação"das ações e as imprescindíveis articulações das equipes profissionais com o movimento estudantil, não podemos deixar de reconhecer que a Assistência Estudantil tem papel fundamental na construção de mecanismos de defesa do direito à educação. Considerados os apontamentos realizados sobre a "Assistência Estudantil Ampliada", acreditamos que ela pode ser considerada uma grande aliada para o fortalecimento das estratégias de universalização da educação no país.

A respeito da evasão escolar, constatamos que as ações de redução da evasão não devem encerrar-se em programas institucionais de acesso e permanência dos estudantes. No IFSP, a ampliação das condições de permanência, por meio de ações institucionalizadas, não será efetiva enquanto a principal razão de evadir for traduzida em trabalho. São necessárias articulações entre órgãos governamentais, educadores, movimentos sociais, estudantes e trabalhadores para que os conhecimentos produzidos sobre esse assunto não se limitem às respostas e estratégias internas das instituições de ensino à evasão. Mas que sejam construídas outras estratégias, em uma esfera ampla envolvendo, principalmente, ministérios e outras instituições governamentais.

Reconhecido o estreito vínculo entre educação e trabalho, é também importante a articulação das instituições de ensino com as lutas sociais trabalhistas. Es- tas constituem esferas para que os direitos dos trabalhadores que estudam, principal público evadido do IFSP, possam ser alargados. Como exemplo, citamos a diminuição da carga horária semanal dos trabalhadores que estudam.

\section{REFERÊNCIAS}

ANDRADE, H. IBGE: um quinto dos jovens no Brasil é "nem-nem", que não estuda nem trabalha. Universo Online (UOL). 2013. Acesso em: 29 nov. 2013.

Disponível em: <http://noticias.uol.com.br/cotidiano/ ultimasnoticias/2013/11/29/.htm.>

ARCOVERDE, A. C. B.; NASCIMENTO, C. M. $O$ Serviço Social na Assistência Estudantil: reflexões acerca da dimensão politico-pedagógica da profissão. FONAPRACE: Revista Comemorativa 25 anos: histórias, memórias e múltiplos olhares. Organizado pelo Fórum Nacional de Pró-reitores de Assuntos Comunitários e Estudantis, coordenação, ANDIFES. 2012. Acesso em: 10 mai. 2013. Disponível em: <http://www.prace.ufop.br/novo/pdfs/fonaprace/ Revista\%20Fonaprace\%2025\%20Anos.pdf $>$

BAGGI, C. A. S.; LOPES, D. A. Evasão e avaliação institucional no ensino superior: uma discussão bibliográfica. Avaliação (Campinas), v. 16, n. 2, p. 355 $-374,2011$.

\section{BEHRING, E.; BOSCHETTI, I. Política social: fundamentos e história. 2. ed. São Paulo, 2007.}

BRASIL. Lei $n^{\circ}$ 11.892, de 29 de dezembro de 2008. Institui a Rede Federal de Educação Profissional, Científica e Tecnológica, cria os Institutos Federais de Educação, Ciência e Tecnologia, e dá outras providências. Brasil, 2008.

Ministério da Educação. Expansão da Rede Federal de Educação Profissional, Científica e Tecnológica. Brasil: [s.n.], 2009. Acesso em: 05 set. 2013. Disponível em: $<$ http://redefederal.mec.gov.br/>

Decreto $n^{\circ}$ 7.234, de 19 de julho de 2010. Dispõe sobre o Programa Nacional de Assistência EstudantilPNAES. Brasil: [s.n.], 2010a. Acesso em: 01 fev. 2012. Disponível em: <http://www.planalto.gov.br/ccivil_03/ _Ato2007-2010/2010/Decreto/D7234.htm>

Ministério da Educação. Um novo modelo de Educação Profissional e Tecnológica. Brasil: [s.n.], 2010b. Acesso em: 01 out. 2013. Disponível em: $<$ http://portal.mec.gov.br/index.phpItemid=\&gid= 6691\&option=com_docman\&task=doc_download $>$ 
DAROS, M. A. O Instituto Federal de Educação, Ciência e Tecnologia de São Paulo (IFSP), a evasão escolar e a atuação do Serviço Social: uma experiência em construção (2008-2009). Dissertação (Mestrado) - Pontifícia Universidade Católica de São Paulo (PUC-SP), Saõ Paulo, 2014.

PEREIRA, P. A. P. Utopias desenvolvimentistas e política social no brasil. Serviço Social \& Sociedade, [online], n. 112, p. 729-753, 2012.

SAVIANI, D. Vicissitudes e perspectivas do direito à educação no brasil: abordagem histórica e situação atual. Educação Social, v. 34, n. 124, p. 743 - 760, 2013.

Silva Filho, R. L. L.; MOTEJUNAS, P. R.; HIPóLITO, O.; LOBO, M. B. C. M. A evasão no ensino superior brasileiro. Cad. Pesqui., v. 37, n. 132, p. $641-659$, 2007.

SILVEIRA, M. M. d. A Assistência Estudantil no Ensino Superior: uma análise sobre as políticas de permanência das universidades federais brasileiras. Dissertação (Mestrado) - Universidade Católica de Pelotas, 2012.

TCU. Acórdão $n^{\circ}$ 506. 2013. Auditoria operacional. Fiscalização de orientação centralizada. Rede federal de educação profissional. 2013. Acesso em: 15 ago. 2013. Disponível em: <http://portal2.tcu.gov.br>

VARGAS, H. M.; PAULA, M. F. C. inclusão do estudante-trabalhador e do trabalhador-estudante na educação superior: desafio público a ser enfrentado. Avaliação (Campinas) [online], v. 18, n. 2, p. 459 485, 2013. 